
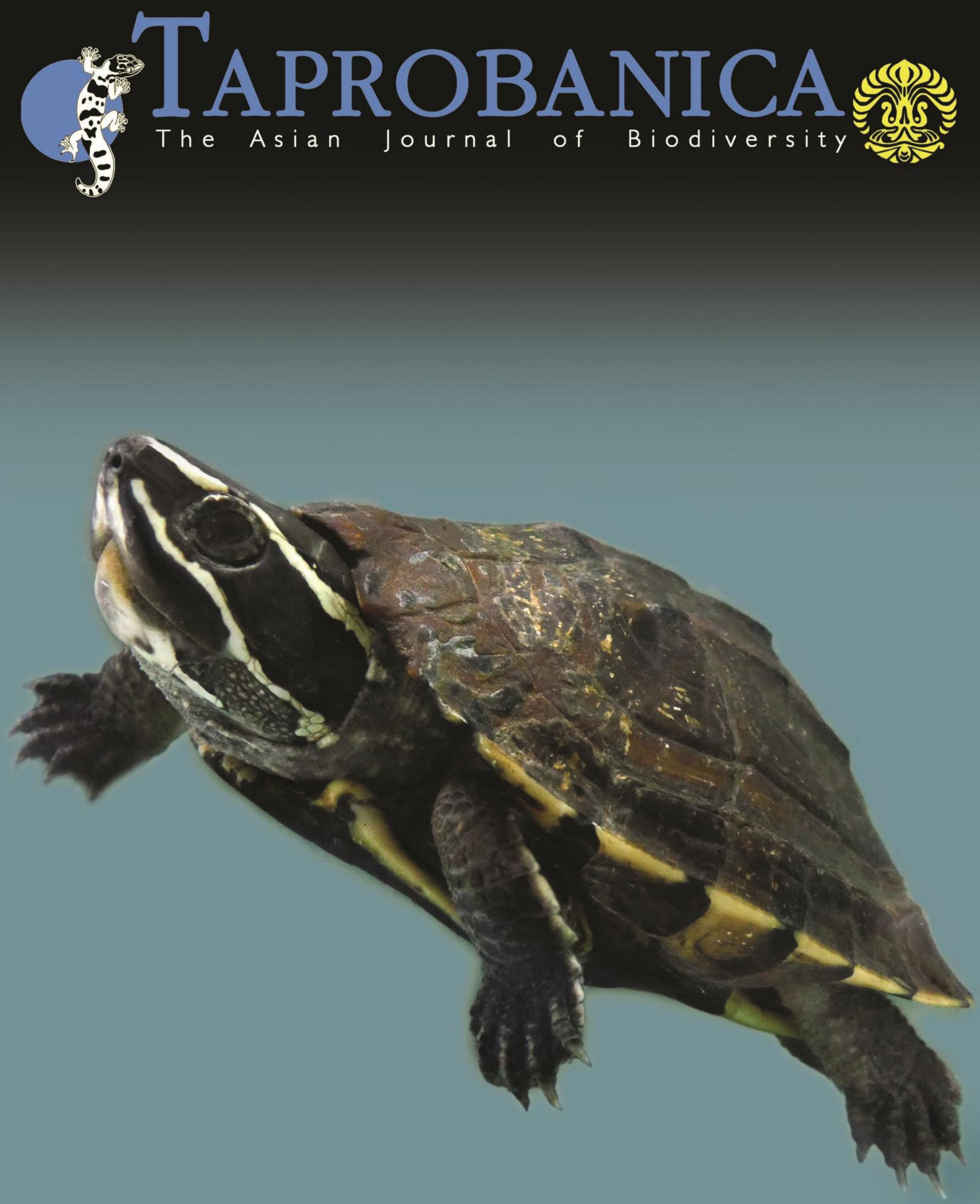
TAPROBANICA, ISSN 1800-427X. March, 2016. Vol. 08, No. 01: pp. 1-9, pls. 1-10. (C) Research Center for Climate Change, University of Indonesia, Depok, Indonesia www.taprobanica.org

\title{
A NEW SNAIL-EATING TURTLE OF THE GENUS Malayemys LINDHOLM, 1931 (GEOEMYDIDAE) FROM THAILAND AND LAOS
}

\author{
Montri Sumontha $^{1}$, Timothy R. Brophy ${ }^{2}$, Kirati Kunya ${ }^{3}$, Suthep Wiboonatthapol ${ }^{4}$ \\ and Olivier S. G. Pauwels ${ }^{5}$
}

\footnotetext{
${ }^{1}$ Ranong Marine Fisheries Station, 157 Saphanpla Rd., Paknam, Muang, Ranong 85000, Thailand; E-mail: montri.sumontha@gmail.com

${ }^{2}$ Department of Biology and Chemistry, Liberty University, 1971 University Boulevard, Lynchburg, Virginia 24502 USA; E-mail: tbrophy@ liberty.edu

${ }^{3}$ Nakhonratchasima Zoo, 111 M. 1, Ratchasima-Pak Tongchai Rd., Chaimongkol, Muang, Nakhon Ratchasima 30000, Thailand; E-mail: kkunya2006@yahoo.com

${ }^{4}$ Khamsaenwittayasan School, 8 M. 10, Na Klang, Na Klang, Nong Bua Lamphu 39170, Thailand;

E-mail: suthepwi@hotmail.com

${ }^{5}$ Département des Vertébrés Récents, Institut Royal des Sciences naturelles de Belgique, Rue Vautier 29, 1000

Brussels, Belgium; E-mail: osgpauwels@yahoo.fr
}

\begin{abstract}
We describe a snail-eating turtle, Malayemys isan sp. nov., from the Mekong River Basin in northeastern Thailand (Nong Bua Lamphu, Nong Khai and Udon Thani provinces) and the adjacent Vientiane area in Laos. The new species is readily distinguishable from M. subtrijuga by its two ( $v s$. six to nine) nasal stripes, and from both $M$. subtrijuga and $M$. macrocephala by its thin, often discontinuous, infraorbital stripe that never reaches the loreal seam. This geographically-restricted new species is sold in several food markets throughout the species' distribution and is in urgent need of conservation measures.
\end{abstract}

Keywords: Aquatic ecosystems, biodiversity, herpetofauna, Mekong, snail-eating turtle

\section{Introduction}

Brophy (2002, 2004, 2005) performed a morphological revision of the genus Malayemys Lindholm, 1931, that was until then regarded by most authors as monospecific, and concluded that it was actually composed of two welldistinguished species, the recognized $M$. subtrijuga (Schlegel \& Müller, 1844) and a taxon he revalidated, M. macrocephala (Gray, 1859). These two species are allopatric and found in different hydrographic basins: while the latter occurs in the Chao Phraya and Mae Khlong river basins, coastal areas of southeastern Thailand and the Malay Peninsula, 
M. subtrijuga is restricted to the Mekong River Basin. Morphometric ratios of both species widely overlap, but they are easy to differentiate based on their number of nasal stripes (four or less in $M$. macrocephala, and six or more in $M$. subtrijuga) and extent/width of infraorbital stripe (not extending beyond the loreal seam, or only slightly in $M$. macrocephala, and extending completely superior to the loreal seam in $M$. subtrijuga; relatively wide at loreal seam in $M$. macrocephala, and relatively narrow at loreal seam in $M$. subtrijuga). The revalidation of $M$. macrocephala by Brophy (2004), based on the thorough examination of more than two hundred specimens from all parts of the genus' range where material was available, has been accepted by many authors working on the Southeast Asian turtle fauna (see among others Pauwels \& Chan-ard, 2006; Keithmaleesatti et al., 2009; Pewphong et al., 2013; Siripiyasing et al., 2013; van Dijk et al., 2014).

In the course of our systematic inventories of the Thai herpetofauna (see latest contribution by Pauwels et al., 2016), we came across a population of Malayemys in northeastern Thailand, in a region that was not represented by the museum material in Brophy's (2004) revision. Even though this population is found in the heart of the Mekong River Basin, where only M. subtrijuga has been found so far (Brophy, 2005), it was strikingly different because of its consistent possession of only two nasal stripes while $M$. subtrijuga shows six or more. We consequently performed a comparison between this population and the two currently recognized species, and conclude that it represents a new taxon, described below.

\section{Materials and Methods}

We examined a total of 223 museum preserved specimens from the whole distribution range of the genus Malayemys (see Appendix I), including the type specimens of $M$. macrocephala and M. subtrijuga, as well as live specimens. We also analyzed all photographs and morphological information available in both the Thai and the international literature (see references in Brophy, 2002, 2004, 2005, and references cited below). The holotype and paratypes of the new species were preserved in $70 \%$ ethanol. Measurements were done on the preserved type series with a vernier caliper to the nearest $0.1 \mathrm{~mm}$. Morphology: CL (maximum carapace length, measured in straight line), $\mathrm{CW}$ (maximum carapace width, measured in straight line), CWV2-3 (carapace width at the level of the seam between $2^{\text {nd }}$ and $3^{\text {rd }}$ vertebrals, measured in straight line), RLPS (relative lengths of plastral scale seams). Abbreviations: $\mathrm{Ab}$, abdominal; An, anal; F, femoral; G, gular; $\mathrm{H}$, humeral; $\mathrm{P}$, pectoral).

Museum abbreviations: CUB, Chulalongkorn University Museum of Zoology, Bangkok, Thailand; IRSNB, Institut Royal des Sciences Naturelles de Belgique, Brussels, Belgium; PSUZC-RT, Prince of Songkhla University Zoological Collection, Reptile section, Songkhla, Thailand; QSMI, Queen Saovabha Memorial Institute, Thai Red Cross Society, Bangkok, Thailand; RMNH.RENA, Rijksmuseum van Natuurlijke Historie (=Netherlands Centre for Biodiversity Naturalis), Leiden, Netherlands; THNHM, Natural History Museum, National Science Museum, Technopolis, Pathum Thani, Thailand; ZMKU, Zoological Museum of Kasetsart University, Bangkok, Thailand.

\section{Results}

Malayemys isan new species

(Figs. 1-6, 7A, 9B, 10; Table 1)

Malayemys subtrijuga—Stuart \& Platt, 2004: 135.

Malayemys subtrijuga-Kubota et al., 2015: 23.

LSID:urn:Isid:zoobank.org:act: 6D1A31B9-8960-42CE -97D5-0F48AF46FD7A

Holotype: THNHM 25609 (field number MS 571), adult female collected from Ban Na Klang $\left(17^{\circ} 14^{\prime} 48.728^{\prime \prime} \mathrm{N}, 102^{\circ} 12^{\prime} 32.479^{\prime \prime} \mathrm{E}\right)$, Na Klang Sub-district, Na Klang District, Nong Bua Lamphu Province, northeastern Thailand.

Paratypes (6 specimens): adult males: ZMKU Rep-000318 (field number MS 573) and PSUZC-RT 716 (field number MS 574); subadult male: QSMI 1396; adult females: CUMZ-R-0.2321 (field number MS 572) and PSUZC-RT 717 (field number MS 575); juvenile: QSMI 1395 (field number MS 577); same locality data as holotype.

Diagnosis: The new species is a medium-sized Malayemys species reaching a maximum carapace length of at least $152 \mathrm{~mm}$ in males and $206 \mathrm{~mm}$ in females, characterized by the consistent combination of (1) only two nasal stripes, (2) a thin, often discontinuous, infraorbital stripe that never reaches the loreal seam, (3) an uninterrupted supraorbital stripe, and (4) the absence of stripes or light spots between the infra- and supraorbital stripes. 
Description of holotype: Adult female. Habitus similar to Malayemys macrocephala and M. subtrijuga. Head large (head width 49.2 $\mathrm{mm}$ ), snout projecting anteriorly. Upper jaw medially notched, with a broad and flat trituring surface and a very slight medial ridge. Carapace oval, moderately arched, unserrated but notched posteriorly. Maximum carapace length 206.3 $\mathrm{mm}$. Maximum carapace width $153.4 \mathrm{~mm}$. Carapace width at the level of the seam between $2^{\text {nd }}$ and $3^{\text {rd }}$ vertebrals $146.1 \mathrm{~mm}$. Cervical scale triangular, pointing forward. Twelve marginal scales on each side. Five vertebral scales, wider than long. Each of the vertebral scales shows a poorly marked median longitudinal keel, higher in the posterior part of each scale. Four pleural scales on each side. The upper part of the $2^{\text {nd }}$ and $3^{\text {rd }}$ pleurals shows a very poorly marked longitudinal keel. Plastron hingeless, narrower than the carapace, notched posteriorly and with strong buttresses. Maximum plastron length $191.3 \mathrm{~mm}$. Hind lobe of the plastron slightly shorter than the bridge. Maximum width of the hind lobe of the plastron $98.2 \mathrm{~mm}$. No intergular scale. Relative lengths of seams between plastral scale pairs: gular < humeral < anal < pectoral < femoral $<$ abdominal seam lengths. The anterior and middle parts of the upper surface of the head are covered by a single large scale limited anteriorly by the nasal scale, anterolaterally by the loreal seam and laterally by the orbit and a very large scale bordering the upper jaw scute. The posterior part of the head upper surface is covered with numerous irregular and much smaller scales. Front surface of forearms showing transversely widened scutes of irregular sizes. Palms of hands and soles of feet covered with small, rounded, juxtaposed scales. Digits strongly webbed; claws moderate.

Coloration in preservative: Vertebrals and pleurals dark brown, lighter near the seams. Plastron light yellow with a large black or dark brown blotch on each scale. Bridges light yellow with two large black blotches on each side. On each side of the head a relatively narrow (sensu Brophy, 2004) cream-colored infraorbital stripe extends from the anterior part of the neck to the lower border of the orbit, and stops well below the loreal seam, from which it is separated by a distance subequal to the distance separating the supraorbital stripe from the loreal seam. On each side a cream-colored supraorbital stripe, beginning in the anterior part of the neck, runs parallel to the infraorbital stripe but extends more anteriorly, passing above the orbit and joining its symmetric stripe, forming in dorsal view a $\mathrm{V}$ on the snout. No additional stripe or light spots between the infraorbital and the supraorbital stripes. Two parallel nasal stripes extend from the nostrils to the medial notch of the upper jaw. Neck, upper surfaces of members and tail gray. Throat light gray with irregular, diffuse, cream spots. Body skin and lower surface of members and tail light gray. Chin scute cream-colored with black markings. One cream- and black-colored large scale on each side of the posterior angular extremity of the chin scute.

Variation: Measurements on the type series are provided in Table 1. The three anterior vertebral scales of CUMZ-R-0.2321 and PSUZC-RT 716 are slightly longer than wide. PSUZC-RT 716 shows a very irregularly-shaped $4^{\text {th }}$ vertebral and only three pleurals on the right side. CUMZ-R-0.2321, ZMKU Rep-000318 and QSMI 1396 show dorsal keels which are more marked than in the holotype, with a higher, nearly continuous keel on vertebrals $1-5$. The development of the keels is most marked in the juvenile QSMI 1395, with a low but continuous keel on vertebrals $1-5$ and on each side on pleurals $1-3$. The relative lengths of the plastral scale seams greatly vary among the types, with the only constant being that the abdominal seam is the longest, followed (in six out of seven cases) by the femoral seam. Some of this variation is probably explained by sexual dimorphism and allometry of plastral scale seam lengths, as was observed in both Malayemys macrocephala (Brophy, 2002, 2006) and $M$. subtrijuga (Brophy, 2002). The juvenile QSMI 1395 and the subadult QSMI 1396 show more extensive dark blotches on the plastral scales than the holotype, and their bridges are nearly totally black. The general coloration of the juvenile QSMI 1395 is the darkest among all type specimens. In CUMZ-R-0.2321 on both sides, in PSUZC-RT 716 on the left side, and in PSUZC-RT 717 on the right side, the infraorbital stripe is thinner than in the holotype, and interrupted in several places below the orbit. Like the holotype, however, the supraorbital stripes of all paratypes are uninterrupted above the orbit. In life, the colors are more contrasted, the light parts of the carapace and plastron and the enlarged scales on the forearm are cream to yellow, and the head stripes are of lighter color than the light parts of the carapace; the eye is black and the pupil is surrounded by a thin cream ring (Figs. 4, 9, 10). Males have longer 
and much thicker tails than females (compare Fig. 1 for females with Figs 2 and 4B for males), as was also observed in both $M$. macrocephala (Brophy, 2002, 2006) and M. subtrijuga (Brophy, 2002).

Etymology: "Isan" is a Thai word designating the northeastern region of Thailand, where the type locality of the new species lies. It is here used as a noun in apposition, invariable. We suggest the following common names: Tao na Isan (Thai), Isan Snail-eating turtle (English), Isan-Schneckenfresser (German), and Malayémyde d'Isan (French).

Distribution and natural history: The species is nocturnal, aquatic and lives in shallow, stagnant or slow-moving freshwater bodies. The type series was collected in the Lampaniang River, which is part of the Nam Phong River system. The river has its source near Ban Na Klang and runs N-NE along Regional Roads 2097-2098-2020 towards Tha Bo District in Nong Khai Province where it flows into the Mekong marking the boundary between Thailand and Laos. The Malayemys macrocephala-morphotype from northeastern Thailand, mentioned without further details by Claude \& Naksri (2014), is probably referrable to Malayemys isan sp. nov. We also refer the individual illustrated by Stuart \& Platt (2004: 135: fig. 18), from Vientiane Municipality, Laos and identified by them as a $M$. subtrijuga, to the new taxon based on its lateral head color pattern showing a thin infraorbital stripe ending below the loreal seam. Kubota et al. (2015: 23) illustrated (under the name M. subtrijuga) a group of Malayemys isan sp. nov. on sale among snails in Thong Khan Kham market in Vientiane. Tha Bo is about 15 airline $\mathrm{km}$ south of Vientiane, and about 65 airline $\mathrm{km}$ from the type locality of Malayemys isan sp. nov. One can expect that the new species occurs in the entire river between $\mathrm{Na}$ Klang and Tha Bo districts. Typical Malayemys macrocephala and
M. subtrijuga were also found on sale in the food markets of the Vientiane area by Suzuki et al. (2015). These authors suggested two possibilities for the occurrence of $M$. macrocephala in Vientiane markets: that individuals were imported from Thailand or Malaysia, or that the species occurs in Laos. In any case, the individual Suzuki et al. (2015) illustrated in their figure $2 \mathrm{C}$ is indeed a $M$. macrocephala, showing four nasal stripes and an infraorbital stripe reaching the loreal seam. There is a possibility that the live individual illustrated by Stuart \& Platt (2004) was an escapee from a market. However, it was caught in the wild while crossing a road near a culvert in May 1999 (i.e. a typical habitat for Malayemys) and, zoogeographically speaking, Vientiane is immediately adjacent to the distributional area of Malayemys isan sp. nov. in Thailand. In addition to the series from Ban $\mathrm{Na}$ Klang, we observed individuals in ditches in Nong Bua Lamphu, Muang District, Nong Bua Lamphu Province and in Udon Thani, Muang District, Udon Thani Province. In Nong Bua Lamphu, the turtles were found in a muddy field flooded with shallow, transparent water, in strict syntopy with the freshwater snakes Homalopsis nigroventralis Deuve, 1970 and Hypsiscopus plumbeus (Boie, 1827) (Homalopsidae) (see Figs. 4, 8, 9A). The broad and flat triturating surface of the upper jaw is an indication that, similar to the other members of this genus, the new species is a specialized snail-eater. In fact, some individuals we kept in captivity readily consumed the indigenous freshwater snail Filopaludina martensi (Frauenfeld, 1864) (Gastropoda: Viviparidae) and exotic freshwater snails of the genus Pomacea Perry, 1810 (Gastropoda: Ampullariidae). This new turtle species is sold in large numbers in the food markets of Ban Na Klang, Nong Bua Lamphu and Udon Thani (MS, pers. obs.; Figs. 9, 10).

Table 1: Measurements (in mm) on the type series of Malayemys isan sp. nov. Abbreviations: See Material and Methods.

\begin{tabular}{|c|c|c|c|c|c|c|c|}
\hline & $\begin{array}{c}\text { THNHM } \\
25609, \\
\text { holotype }\end{array}$ & $\begin{array}{c}\text { CUMZ-R- } \\
0.2321, \\
\text { paratype }\end{array}$ & $\begin{array}{c}\text { ZMKU Rep- } \\
\text { 000318, } \\
\text { paratype }\end{array}$ & $\begin{array}{c}\text { PSUZC-RT } \\
716, \\
\text { paratype } \\
\end{array}$ & $\begin{array}{c}\text { PSUZC-RT } \\
717, \\
\text { paratype }\end{array}$ & $\begin{array}{c}\text { QSMI } \\
1396, \\
\text { paratype }\end{array}$ & $\begin{array}{c}\text { QSMI } \\
1395, \\
\text { paratype }\end{array}$ \\
\hline Sex & female & female & male & male & female & $\begin{array}{l}\text { subadult } \\
\text { male }\end{array}$ & juvenile \\
\hline CL & 206.3 & 143.4 & 138.2 & 152.4 & 186.5 & 99.2 & 67.5 \\
\hline $\mathrm{CW}$ & 153.4 & 102.0 & 99.5 & 107.5 & 139.1 & 77.1 & 53.3 \\
\hline CWV2-3 & 146.1 & 100.4 & 98.3 & 106.3 & 138.2 & 76.2 & 53.2 \\
\hline RLPS & $\begin{array}{l}\mathrm{G}<\mathrm{H}<\mathrm{An} \\
<\mathrm{P}<\mathrm{F}<\mathrm{Ab}\end{array}$ & $\begin{array}{c}\mathrm{H}<\mathrm{An}<\mathrm{P}< \\
\mathrm{G}<\mathrm{F}<\mathrm{Ab}\end{array}$ & $\begin{array}{c}\mathrm{H}<\mathrm{G}<\mathrm{An}<\mathrm{P} \\
<\mathrm{F}<\mathrm{Ab}\end{array}$ & $\begin{array}{c}\mathrm{H}<\mathrm{An}<\mathrm{G}< \\
\mathrm{F}<\mathrm{P}<\mathrm{Ab}\end{array}$ & $\begin{array}{c}\mathrm{H}<\mathrm{G}<\mathrm{An}< \\
\mathrm{P}<\mathrm{F}<\mathrm{Ab}\end{array}$ & $\begin{array}{l}\mathrm{An}<\mathrm{H}<\mathrm{G} \\
<\mathrm{P}<\mathrm{F}<\mathrm{Ab}\end{array}$ & $\begin{array}{c}\mathrm{H}<\mathrm{An}<\mathrm{G}< \\
\mathrm{P}<\mathrm{F}<\mathrm{Ab}\end{array}$ \\
\hline
\end{tabular}


Comparison with other species: Brophy (2002, 2004) re-examined the three syntypes of Malayemys subtrijuga (RMNH.RENA 6082, 6084-5); they all show six nasal stripes and an infraorbital stripe that is relatively narrow at the loreal seam and that extends completely superior to the loreal seam to join the supraorbital stripe. Brophy (2004) designated RMNH.RENA 6082 (illustrated by Hoogmoed et al., 2010: fig. 4, captioned with an erroneous "RMNH.RENA 6682 " number) as lectotype of $M$. subtrijuga. Besides the material we examined from all parts of the distribution of M. subtrijuga (see Brophy, 2004, and Appendix below), many published illustrations of this species show the possession of six or more nasal stripes and the prolongation of the infraorbital stripe above the loreal seam (among many others, Rödder et al., 2013: 16; Ihlow et al., 2015: 19). Both of these characters readily distinguish $M$. subtrijuga from Malayemys isan sp. nov.

We examined the infraorbital stripe in 137 preserved specimens of Malayemys macrocephala (see Brophy, 2004, and Appendix below). All of them show, on both sides of the head, an infraorbital stripe that reaches the loreal seam, or goes just above it. In addition to this material, we examined many published photographs and drawings of $M$. macrocephala, including the plate accompanying the original description of the species by Gray (1859), illustrating the wide infraorbital stripe reaching, or going just beyond, the loreal seam. These published figures represent individuals from the provinces of Ayutthaya (Pewphong et al., 2013: 256; the studies by Keithmaleesatti, 2008; Keithmaleesatti et al., 2009; and Tunsaringkarn et al., 2012, 2013 are based on turtles obtained from the same locality), Bangkok (Juschka, 2009: 21, under M. subtrijuga, from Lumphini Park), Krabi (Mudde, 1991: 100, under Malayemys trijuga), Nakhon Ratchasima (Manthey \& Grossmann, 1997: 450, under $M$. subtrijuga; Chan-ard et al., 1999: 226, under $M$. subtrijuga), Phetchaburi (Pauwels \& Chan-ard, 2006: 99) or unspecified Thai localities (Thirakhupt \& van Dijk, 1994: 231, under $M$. subtrijuga; Ninwanit, 1995: 17; Nutaphand, 2000: 130, under $M$. subtrijuga; Turtle Conservation Fund, 2002: 21, under $M$. subtrijuga; La-ong, 2009; Thirakhupt et al., 2011; Chan-ard et al., 2015: 39). This character state is consistently present in $M$. macrocephala and can be used to easily distinguish it from Malayemys isan sp. nov. The new species is also readily distinguishable from all $M$. macrocephala individuals showing additional stripes or spots between the infra- and supraorbital stripes (see Figs. 7B, 8A), absent in Malayemys isan sp. nov., and/or four nasal stripes (see Fig. 8A).

Although Malayemys isan sp. nov. is, among the Malayemys spp., the species whose lateral head stripes are the least developed, all Malayemys spp. specimens we examined and all published photographs of live or preserved individuals show very distinct lateral head stripes. Damonia crassiceps, described from China by Gray (1870) who placed it with doubt in the genus Damonia Gray, 1869 and tentatively placed by Smith (1931: 105) in the synonymy of Damonia subtrijuga, certainly does not belong to the synonymy of that species nor to the genus Malayemys because, among other things, the original description clearly states that it does not have markings on the sides of the head. It should also be noted that Smith (1931) illustrated Malayemys subtrijuga with an excellent head drawing of $M$. macrocephala, showing a wide infraorbital stripe extending just above the loreal seam but not joining the supraorbital stripe.

In addition to the Javan material seen by Brophy (2004), we examined two more preserved individuals (IRSNB $187 \gamma-\delta$ ) from the island, and both show infraorbital stripes going above the loreal seam. IRSNB $187 \delta$ shows six nasal stripes; IRSNB $187 \gamma$ shows at least four (the head is partly discolored). This supports the identification of the Javan population by Brophy (2004) and the synonymy of the presumably Javan Emys nuchalis Blyth, 1863 as $M$. subtrijuga (Das et al., 1998). The original description of the Indonesian Damonia oblonga by Gray (1871) clearly states that it has three vertical stripes on each side of the nose, excluding a conspecificity with the new species.

\section{Discussion}

In spite of the revision of the genus by Brophy (2004), providing straight forward chromatical characters to separate Malayemys macrocephala and $M$. subtrijuga, two recent field guides created some confusion in the identification of Malayemys spp. Das (2010) illustrated Malayemys subtrijuga with the drawing of a $M$. macrocephala, and Chan-ard et al. (2015), in their key to the genus Malayemys, erroneously stated that $M$. subtrijuga has an "upper jaw with three vertical lines" (corrected to "three pairs of 
vertical lines"'by Pauwels \& Grismer, 2015). Moreover, Chan-ard et al. (2015: 40) indicated that the supraorbital stripe of $M$. subtrijuga is "broken behind the eye"; this condition, however, is not at all constant in $M$. subtrijuga (see for example the photographs of individuals with unbroken supraorbital stripe in Thirakhupt \& van Dijk, 1994 and Brophy, 2004).

The combination of the numbers and state of the nasal and infraorbital stripes is a reliable and easy character to differentiate the three species of Malayemys. The new Malayemys population identified here is clearly distinguishable from the two currently recognized species in the genus, and none of the synonyms for either of these two species is applicable to it. Brophy (2002: 75) wrote "If overexploited populations of $M$. subtrijuga [sensu lato] represent cryptic taxa, it is imperative that they are discovered and described (...)'. In view of the restricted distribution of the new species and its local exploitation, it is indeed of immediate importance that it receives a name and hence gets the attention and benefits from urgently needed conservation actions.

The new species lives in the Mekong River Basin, where M. subtrijuga also occurs, although not in sympatry. Besides the small area occupied by Malayemys isan sp. nov. and some individuals from Vientiane markets discussed above and probably imported, all the rest of the Mekong Basin is inhabited by populations showing at least six nasal stripes and an infraorbital stripe going above the loreal seam and being clearly referrable to $M$. subtrijuga (see for example photographs and remarks in Hartmann et al., 2013 for Cambodia, and photographs in Dang et al., 2006: 53 and photographs and drawing in Hendrie et al., 2010: 9 for southern Vietnam). Geographically Malayemys isan sp. nov. is thus closer to $M$. subtrijuga. In terms of pattern, its two nasal stripes put it closer to M. macrocephala, but its relatively thin infraorbital stripe puts it closer to M. subtrijuga. It is possible that future genetic studies could demonstrate a closer relationship with $M$. macrocephala or $M$. subtrijuga. However, since this morphologically distinct population is hydrographically isolated at present, it should be considered an independently evolving entity and be afforded full species status (Simpson, 1961; Wiley, 1978, 1980; Frost \& Hillis, 1990). These are the same criteria and species concept used by Brophy
(2004) to recognize $M$. macrocephala and $M$. subtrijuga as full and separate species.

This description of Malayemys isan sp. nov. requires a revision of the known distribution range of $M$. subtrijuga. The area of occurrence of the new species, included in the distribution map for $M$. subtrijuga given by van Dijk et al. (2014: 380) and presumably taking into account the Vientiane record by Stuart \& Platt (2004), has to be removed from the map for the latter species, as there is currently no indication that the species' distributions naturally overlap. The differentiation of Malayemys isan sp. nov. probably finds its explanation in the relative isolation of this part of the Mekong River Basin compared to the other hydrographical systems in mainland southeast Asia (see discussion in Claude et al., 2011 on hypotheses of past connections between the Mekong and other river systems based on Neogene fossil aquatic reptiles).

Two individuals found in an irrigation ditch near Pak Chong, Pak Chong District, in Nakhon Ratchasima Province illustrated in Manthey \& Grossmann (1997) and Chan-ard et al. (1999), identified by these authors as $M$. subtrijuga, are clearly referrable to $M$. macrocephala based on their head patterns (two nasal stripes and a wide infraorbital stripe reaching, but not going beyond, the loreal seam). This locality is very close to the westernmost record of M. subtrijuga in Sakaerat, Pak Thong Chai District, Nakhon Ratchasima Province (based on our examination of CUB 1993.01.16.2 and CUB 1993.01.16.9). However, even though these localities are very close, they are hydrographically linked to the Chao Phraya and Mekong river basins, respectively, and confirm that $M$. subtrijuga is restricted to the Mekong River Basin where M. macrocephala does not penetrate. The geographic proximity of these localities also confirms the poor dispersal abilities of Malayemys spp., restricted by hilly areas and unable to ascend streams as noted by Thirakhupt \& van Dijk (1994) and Brophy (2002, 2004).

The conservation status of Malayemys subtrijuga has been evaluated as Vulnerable by the IUCN (Asian Turtle Trade Working Group, 2000). However, this evaluation took place before the revision of the genus by Brophy (2004), when $M$. macrocephala was not yet revalidated and the genus was believed to be composed of a single, widespread species. Malayemys isan sp. nov. occupies a very small 
fraction of the entire range of the genus Malayemys. There is evidence that it is harvested throughout its distribution. It is not yet recorded from a protected area and does not benefit of any specific conservation action. Urgently-needed field studies should determine if Malayemys isan sp. nov. qualifies for the Vulnerable or Endangered IUCN categories.

\section{Acknowledgments}

We thank the Department of Fisheries, Thai Ministry of Agriculture and Cooperatives, for supporting our field work. We are grateful to Kumthorn Thirakhupt (CUB, Bangkok), Sébastien Bruaux, Tom Geerinckx and Georges L. Lenglet (IRSNB, Brussels), Sansareeya Wangkulangkul (PSUZC, Songkhla), Lawan Chanhome (QSMI, Bangkok), Tanya Chan-ard (THNHM, Pathum Thani) and Wut Taksintum (ZMKU, Bangkok) for working facilities, to Noppadon Kitana (CUB, Bangkok) and Dai Suzuki (Kyushu University) for providing useful information, and to Cholapat Jeerapornphand, Thanin Kaewmanee, Chadarat Ngamsom and Teerawat Utapong for their assistance in the field. Finally we would like to thank two anonymous reviewers for their valuable comments.

\section{Literature cited}

Asian Turtle Trade Working Group, 2000. Malayemys subtrijuga. The IUCN Red List of Threatened Species 2000: e.T39555A10248240.

Blyth, E., 1863. Report of the Curator, Zoological Department. Proceedings of the Asiatic Society of Bengal, 32: 79-90.

Brophy, T. R., 2002. Variation and systematics of the Malayan Snail-eating Turtle, Malayemys subtrijuga (Schlegel and Müller, 1844). $P h D$ thesis, George Mason University, Fairfax.

Brophy, T. R., 2004. Geographic variation and systematics in the South-east Asian turtles of the genus Malayemys (Testudines: Bataguridae). Hamadryad, 29: 63-79.

Brophy, T. R., 2005. Geographic distribution of the Southeast Asian turtles in the genus Malayemys (Testudines: Bataguridae). Bulletin of the Chicago Herpetological Society, 40: 21-33.

Brophy, T. R., 2006. Allometry and sexual dimorphism in the snail-eating turtle Malayemys macrocephala from the Chao Phraya River Basin of central Thailand. Chelonian Conservation and Biology, 5: 159-165.

Chan-ard, T., W. Grossmann, A. Gumprecht and K.-D. Schulz, 1999. Amphibians and reptiles of Peninsular Malaysia and Thailand. An illustrated checklist. Amphibien und Reptilien der Halbinsel Malaysia und Thailands. Eine illustrierte Checkliste. Bushmaster Publications, Wuerselen: 240.

Chan-ard, T., J. W. K. Parr and J. Nabhitabhata, 2015. A Field Guide to the Reptiles of Thailand. Oxford University Press, New York: xxix+314.

Claude, J. and W. Naksri, 2014. Les pratiques bouddhistes ont elles modifié la zone de contact entre Malayemys macrocephala et Malayemys subtrijuga en Thailande? [in French]. In: 8ème Symposium national de morphométrie et d'évolution des formes. Université de Bourgogne, Dijon: 15.

Claude, J., W. Naksri, N. Boonchai, E. Buffetaut, J. Duangkrayom, C. Laojumpon, P. Jintasakul, K. Lauprasert, J. Martin, V. Suteethorn and H. Tong, 2011. Neogene reptiles of northeastern Thailand and their paleogeographical significance. Annales de Paléontologie, 97: 113-131.

Dang, H. P., Q. T. Nguyen, T. S. Nguyen, and V. K. Nguyen, 2006. A photographic guide to mammals, reptiles and amphibians of Phu Quoc Island, Kien Giang Province, Vietnam. Wildlife at Risk, Ho Chi Minh: 73.

Das, I., 2010. A field guide to the reptiles of Southeast Asia. New Holland Publishers (UK) Ltd, London: 376.

Das, I., B. Dattagupta, and N. C. Gayen, 1998. History and catalogue of reptile types in the collection of the Zoological Survey of India. Journal of South Asian Natural History, 3: 121172.

Frost, D. R. and D. M. Hillis, 1990. Species in concept and practice: herpetological applications. Herpetologica, 46: 87-104.

Gray, J. E., 1859. Description of a new species of freshwater tortoise from Siam. Proceedings of the Zoological Society of London, 1859: 478-479.

Gray, J. E., 1870. Supplement to the catalogue of shield reptiles in the collection of the British Museum. Part I. Testudinata (Tortoises). Taylor and Francis, London: 120. 
Gray, J. E., 1871. Damonia oblonga, a new species of freshwater tortoise. Annals and Magazine of Natural History, 4: 367.

Hartmann, T., F. Ihlow, S. Edwards, S. Sovath, M. Handschuh, and W. Böhme, 2013. A preliminary annotated checklist of the amphibians and reptiles of the Kulen Promtep Wildlife Sanctuary in northern Cambodia. Asian Herpetological Research, 4: 36-55.

Hendrie, D. B., Bùi Đăng Phong, T. McCormack, Hoàng Văn Hà, and P. P. van Dijk, 2010. Sách hướng dẫn thi hành luật về định dạng các loài rùa cạ và rùa nưóc ngọt Viet Nam [in Vietnamese]. Trung tâm Bảo tồn thiên nhiên xuất bản, Hà Nội: 67.

Hoogmoed, M. S., M. E. Gassó Miracle, and L. W. van den Hoek Ostende, 2010. Type specimens of recent and fossil Testudines and Crocodylia in the collections of the Netherlands Centre for Biodiversity Naturalis, Leiden, the Netherlands. Zoologische Mededelingen Leiden, 84: 159-199, figs 1-13.

Ihlow, F., T. Hartmann, P. Geissler, and D. Rödder, 2015. Biodiversitätsforschung, Ökologie und Verbreitung der Herpetofauna Südostasiens [in German]. In: Jahresbericht 2013/14. Zoologisches Forschungsmuseum Koenig, Bonn: 17-19.

Juschka, M., 2009. Auf "Waransuche" in Bangkok. In: N. Joswig (ed.). Terraristika 36. Natur und Tier - Verlag GmbH, Münster: 20-22.

Keithmaleesatti, S., 2008. An assessment of the association of organochlorine pesticide contamination and reproductive effects on the snail-eating turtle (Malayemys macrocephala) in the lower Chao Phraya River basin, Thailand. Ph.D. thesis, Chulalongkorn University, Bangkok.

Keithmaleesatti, S., P. Varanusupakul, W. Siriwong, K. Thirakhupt, M. Robson, and N. Kitana, 2009. Contamination of organochlorine pesticides in nest soil, egg, and blood of the snaileating turtle (Malayemys macrocephala) from the Chao Phraya River Basin, Thailand. International Journal of Biological, Biomolecular, Agricultural, Food and Biotechnological Engineering, 3: 193198.

Kubota, M., S. Saito, S. Ichikawa, M. Kaneko, S. Fuchigami, A. Imamura and K. Ishibashi, 2015. Mizube no Sachi. Gift of Waterfront. Illustrated Handbook of Edible Plants and Animals
Indigenous to the Mekong River Basin. Nagao Natural Environment Foundation, Tokyo: 445.

La-ong, S., 2009. Karnjamnek Tao na [Characterization of rice-field turtles] [in Thai]. Wildlife Yearbook, 9 (2008): 178-182.

Manthey, U. and W. Grossmann, 1997. Amphibien \& Reptilien Südostasiens. Natur und Tier - Verlag, Münster: 512.

Mudde, P., 1991. Terrariumdieren in Thailand [in Dutch]. Lacerta, 49: 98-108.

Ninwanit, S., 1995. [Secrets for the professional breeding of softshell turtles] [in Thai]. Matichon Company Ltd, Bangkok: 108.

Nutaphand, W., 2000. The Turtles of Thailand [in Thai]. Prime Minister's Office, Bangkok: 208.

Pauwels, O. S. G. and T. Chan-ard, 2006. Reptiles of Kaeng Krachan National Park, western Thailand. Natural History Bulletin of the Siam Society, 54: 87-106.

Pauwels, O. S. G. and L. L. Grismer, 2015. Book review. A Field Guide to the Reptiles of Thailand. Herpetological Review, 46: 456-459.

Pauwels, O. S. G., M. Sumontha, and A. M. Bauer, 2016. A new Bent-toed Gecko (Squamata: Gekkonidae: Cyrtodactylus) from Phetchaburi Province, Thailand. Zootaxa, 4088: 409-419.

Pewphong, R., J. Kitana and N. Kitana, 2013. Effect of incubation temperature on the somatic development of the snail-eating turtle Malayemys macrocephala. Asian Herpetological Research, 4: 254-262.

Rödder, D., M. Flecks and A. Koch, 2013. Amphibien und reptilien: wo stehen die Kriechtiere in der Globalen Biodiversitätskrise? [in German]. In: Jahresbericht 2012. Zoologisches Forschungsmuseum Koenig, Bonn: 15-16.

Simpson, G. G., 1961. Principles of Animal Taxonomy. Columbia University Press, New York: 247.

Siripiyasing, P., A. Tanomtong, S. Jumrusthanasan, I. Patawang, S. Phimphan, and L. Sanoamuang, 2013. First cytogenetic study of Malayan Snail-eating Turtle, Malayemys macrocephala (Testudines, Geoemydidae) in Thailand. Cytologia, 78: 125-132. 
Smith, M. A., 1931. The fauna of British India, including Ceylon and Burma. Reptilia and Amphibia. Vol. I. - Loricata, Testudines. Taylor and Francis, London: xxvi+185+2 pl.

Stuart, B. L. and S. G. Platt, 2004. Recent records of turtles and tortoises from Laos, Cambodia, and Vietnam. Asiatic Herpetological Research, 10: 129-150.

Suzuki, D., K. Fuse, M. Aizu, S. Yoshizawa, W. Tanaka, K. Araya, and B. Praxaysombath, 2015. Reptile diversity in food markets in Laos. Current Herpetology, 34: 112-119.

Thirakhupt, K., C. Lekprayoon, N. Janthsawat, T. Phupradit, and T. Bundhitwongrut, 2011. Phiphithapan Tao [Turtle Museum] [in Thai]. Chulalongkorn University Museum of Natural History, Bangkok: 72.

Thirakhupt, K. and P. P. van Dijk, 1994. Species diversity and conservation of the turtles of western Thailand. Natural History Bulletin of the Siam Society, 42: 207-259.

Tunsaringkarn, T., W. Tungjaroenchai, and W. Siriwong, 2012. Mineral compositions of chicken', quail' and snail-eating turtle's eggs. Journal of Health Research, 26: 59-63.
Tunsaringkarn, T., W. Tungjaroenchai, and W. Siriwong, 2013. Determination of chemical compositions of snail-eating turtle (Malayemys macrocephala) eggs. Agriculture Science Developments, 2: 31-39.

Turtle Conservation Fund, 2002. A Global Action Plan for Conservation of Tortoises and Freshwater Turtles. Strategy and Funding Prospectus 20022007. Conservation International and Chelonian Research Foundation, Washington, DC: 30.

Van Dijk, P. P., J. B. Iverson, A. G. J. Rhodin, H. B. Shaffer, and R. Bour, 2014. Turtles of the World, $7^{\text {th }}$ edition: annotated checklist of taxonomy, synonymy, distribution with maps, and conservation status. Chelonian Research Monographs, 5: 329-479.

Wiley, E. O., 1978. The evolutionary species concept reconsidered. Systematic Zoology, 27: 1726.

Wiley, E. O., 1980. Is the evolutionary species fiction? - A consideration of classes, individuals, and historical entities. Systematic Zoology, 29: 7680 .

\section{Appendix I: Comparative material examined}

Malayemys macrocephala: 134 specimens listed in Brophy (2004: 76); QSMI 1397 (field nr MS 578): Phatthalung Province, southern Thailand; IRSNB 187e, "Batavia" [=Jakarta, Indonesia]; IRSNB 15037: "Doi Suthep, Chiang Mai Province, northern Thailand" ("specimen found immobile on the side of a mountain waterfall, probably released for religious purposes").

Malayemys subtrijuga: 74 specimens listed in Brophy (2004: 76); QSMI 1398-1399 (field nrs MS 576 and MS 579, respectively): Surin Province, eastern Thailand; IRSNB $187 \gamma-\delta$ : "Java"; IRSNB 15036, "Chiang Mai, Chiang Mai Province, northern Thailand" ("bought in a food market where it was sold for consumption"). 


\section{PLATE 1}
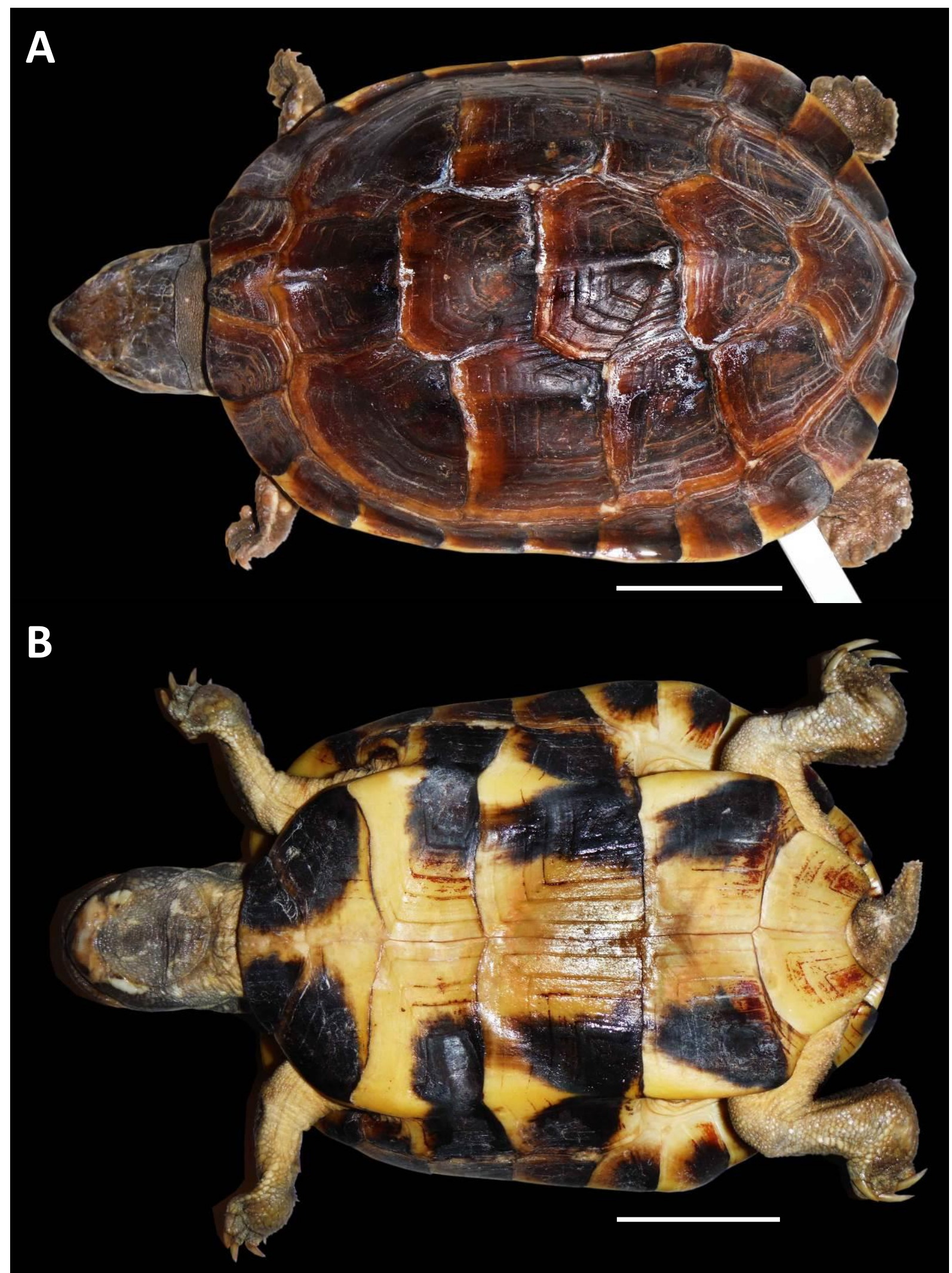

Figure 1: The adult female holotype (THNHM 25609) of Malayemys isan sp. nov. (A) dorsal view, (B) ventral view): scale $=5 \mathrm{~cm}$. 


\section{PLATE 2}

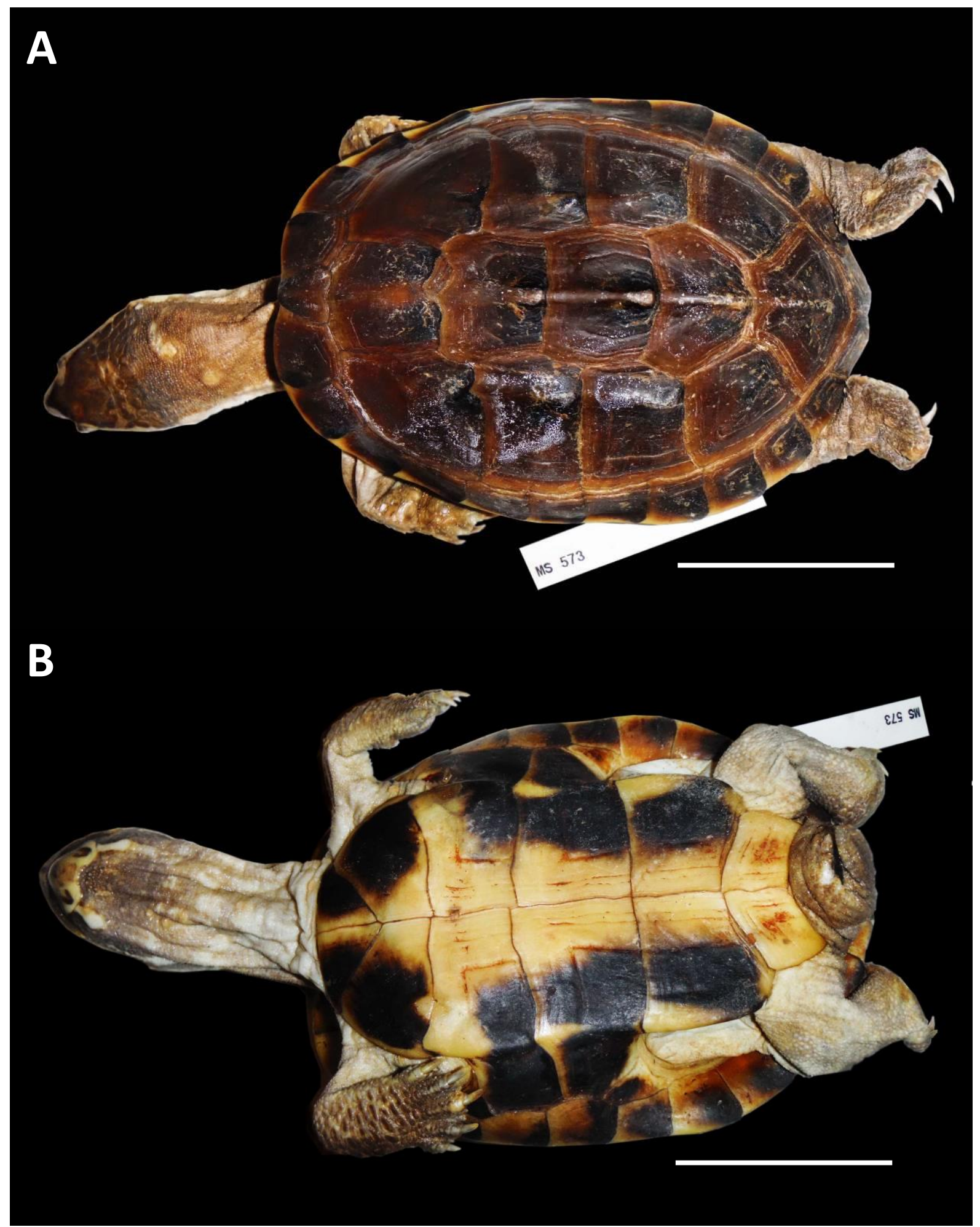

Figure 2: An adult male paratype (ZMKU Rep-000318) of Malayemys isan sp. nov. (A) dorsal view, (B) ventral view: scale $=5 \mathrm{~cm}$. 


\section{PLATE 3}

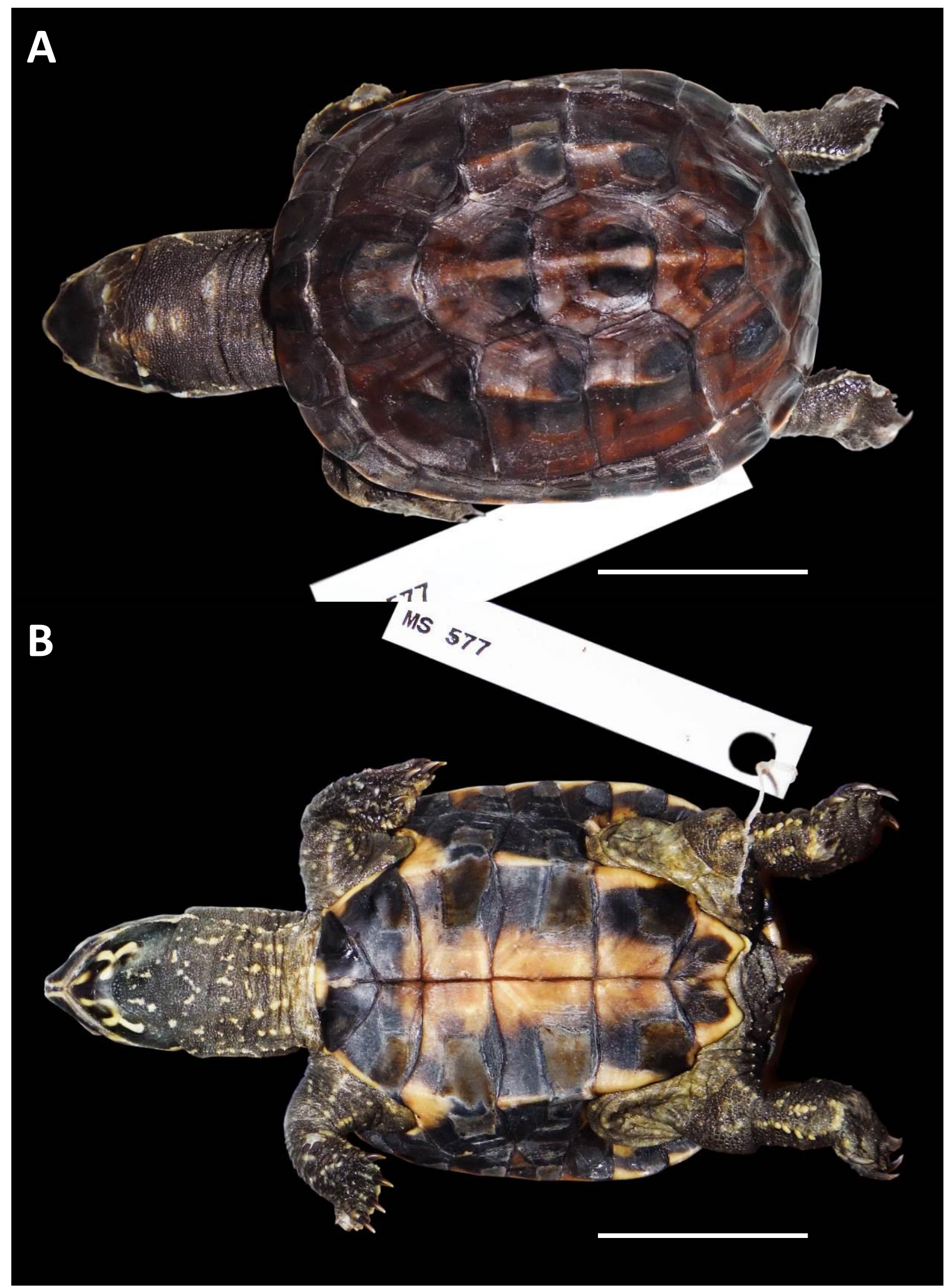

Figure 3: A juvenile paratype (QSMI 1395) of Malayemys isan sp. nov. (A) dorsal view, (B) ventral view: scale $=2.5 \mathrm{~cm}$. 


\section{PLATE 4}
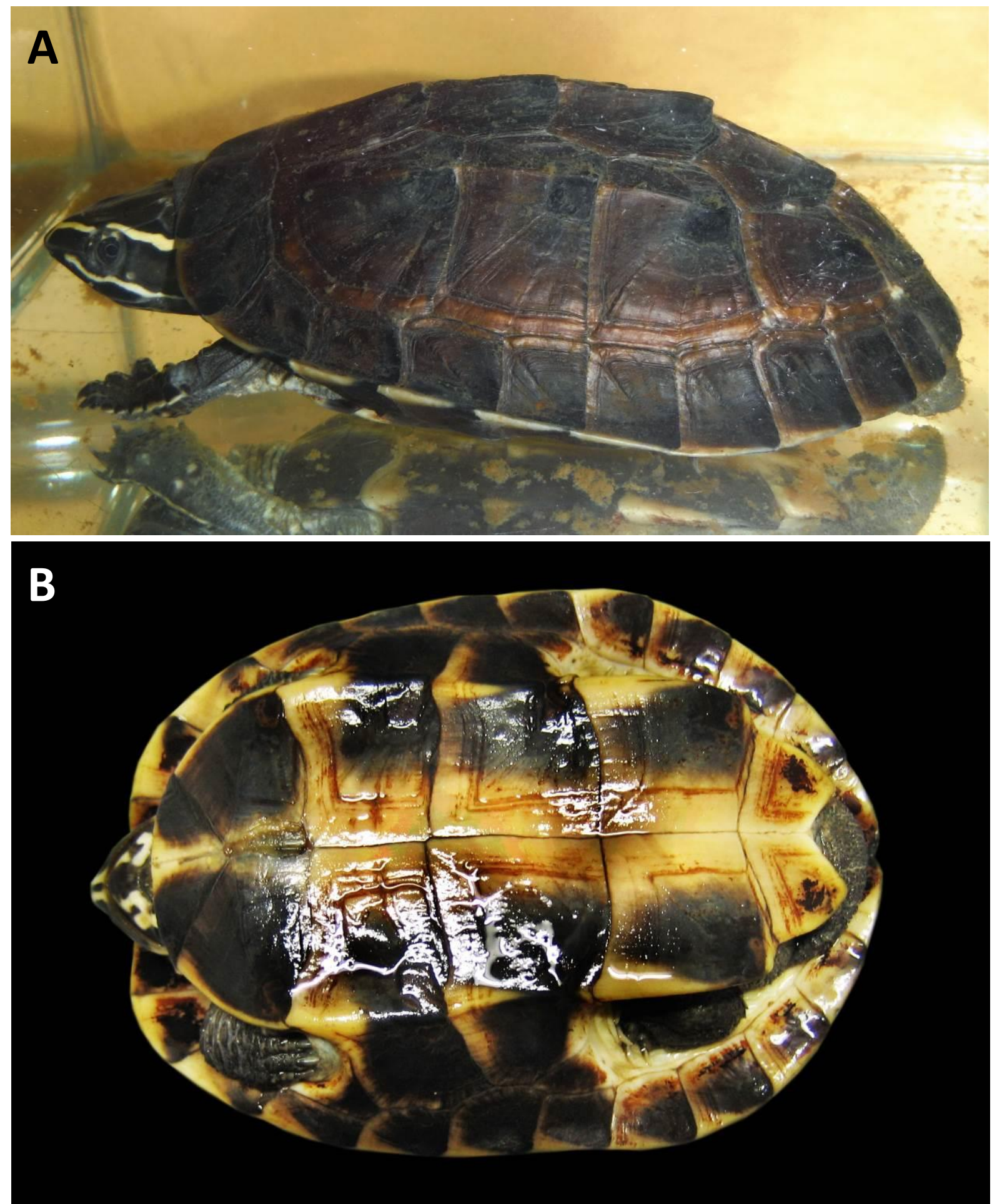

Figure 4: Live adult Malayemys isan sp. nov., not preserved, (A) female from Nong Bua Lamphu, (B) male from Udon Thani (ventral view). 


\section{PLATE 5}

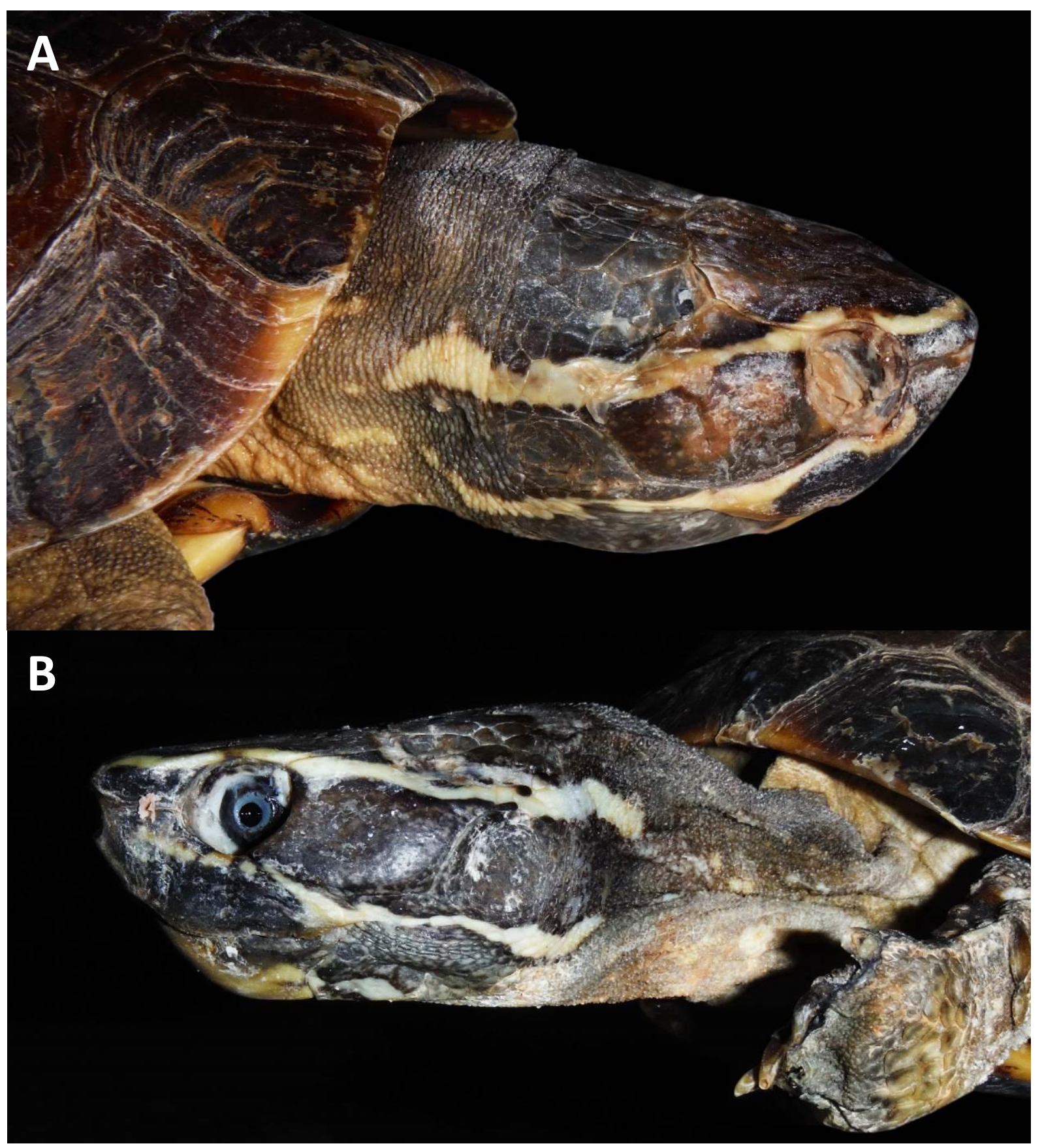

Figure 5: Lateral head views of type specimens of Malayemys isan sp. nov. (A) Holotype, right side, (B) Paratype CUMZ-R-0.2321, left side, 


\section{PLATE 6}

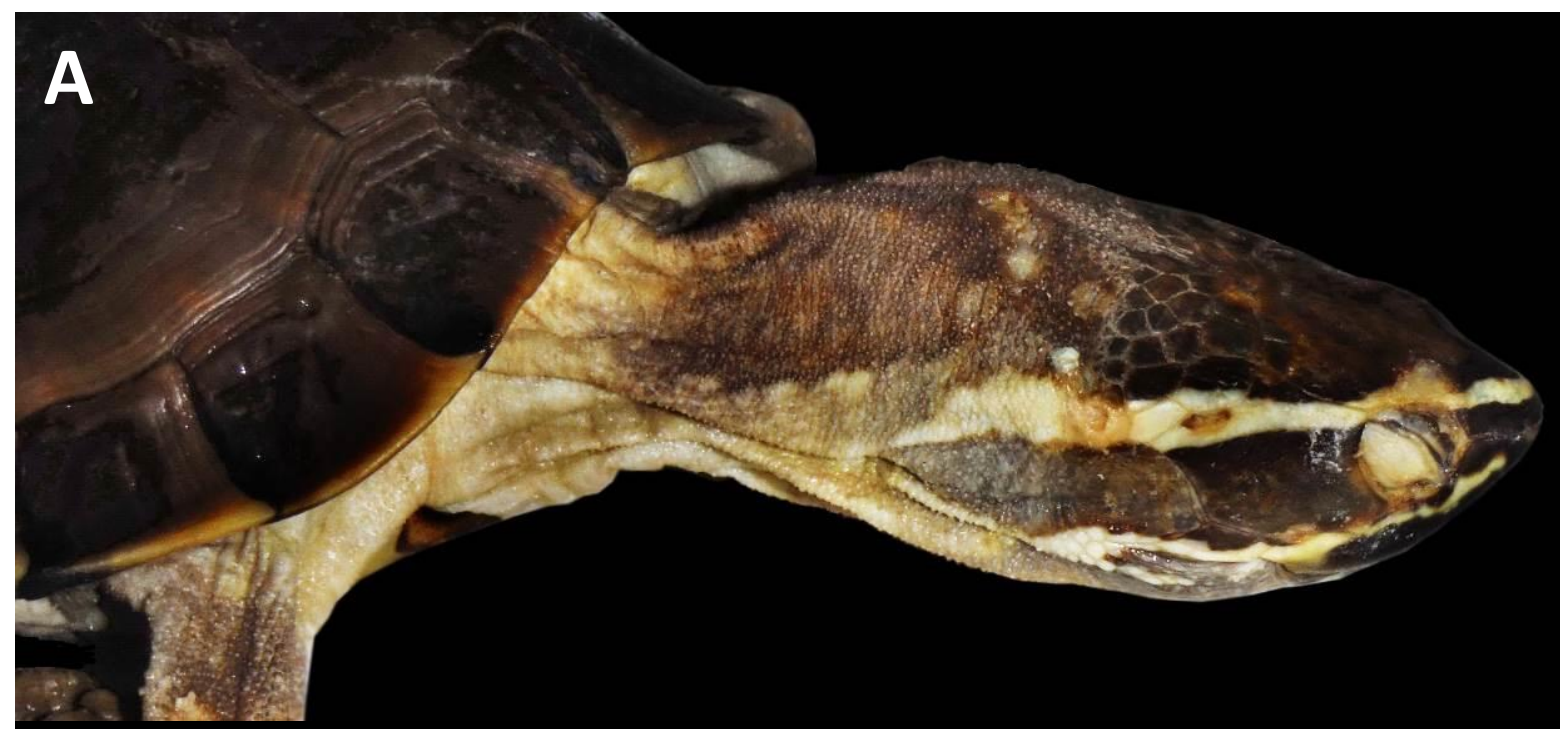

B

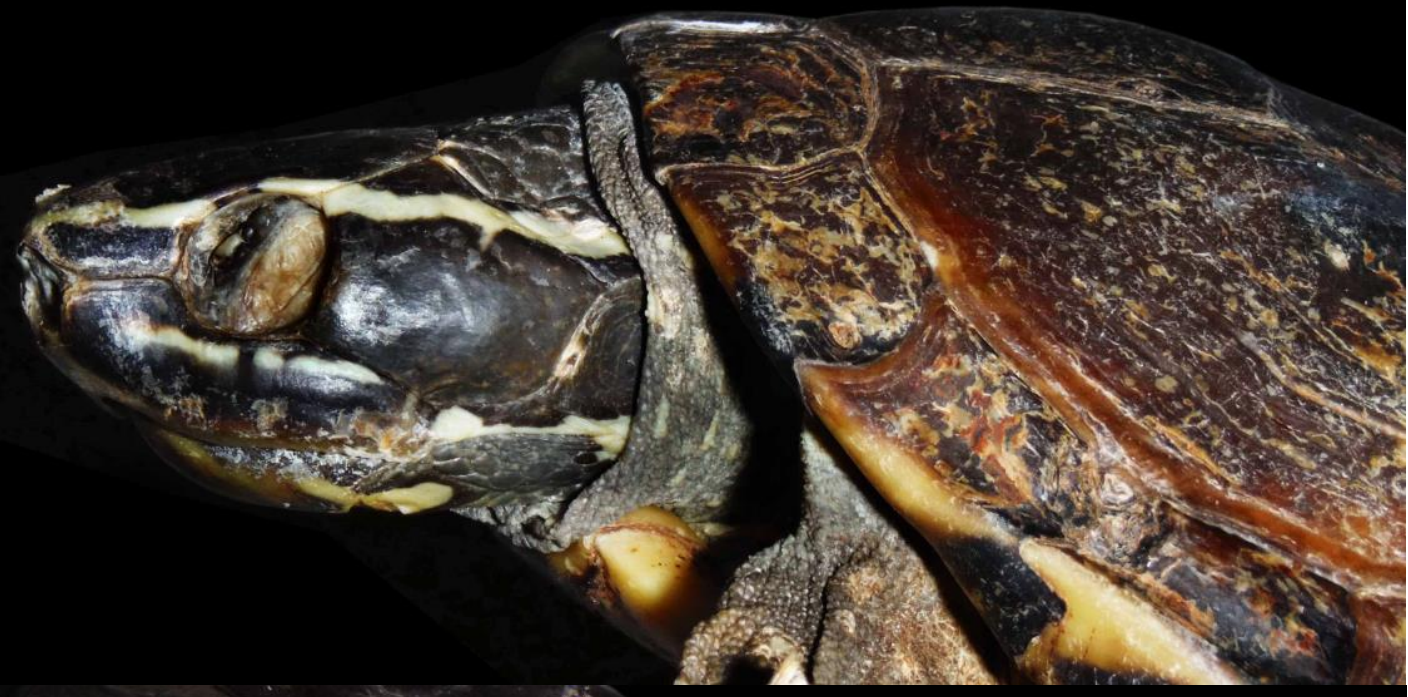

C

$\operatorname{sen}$

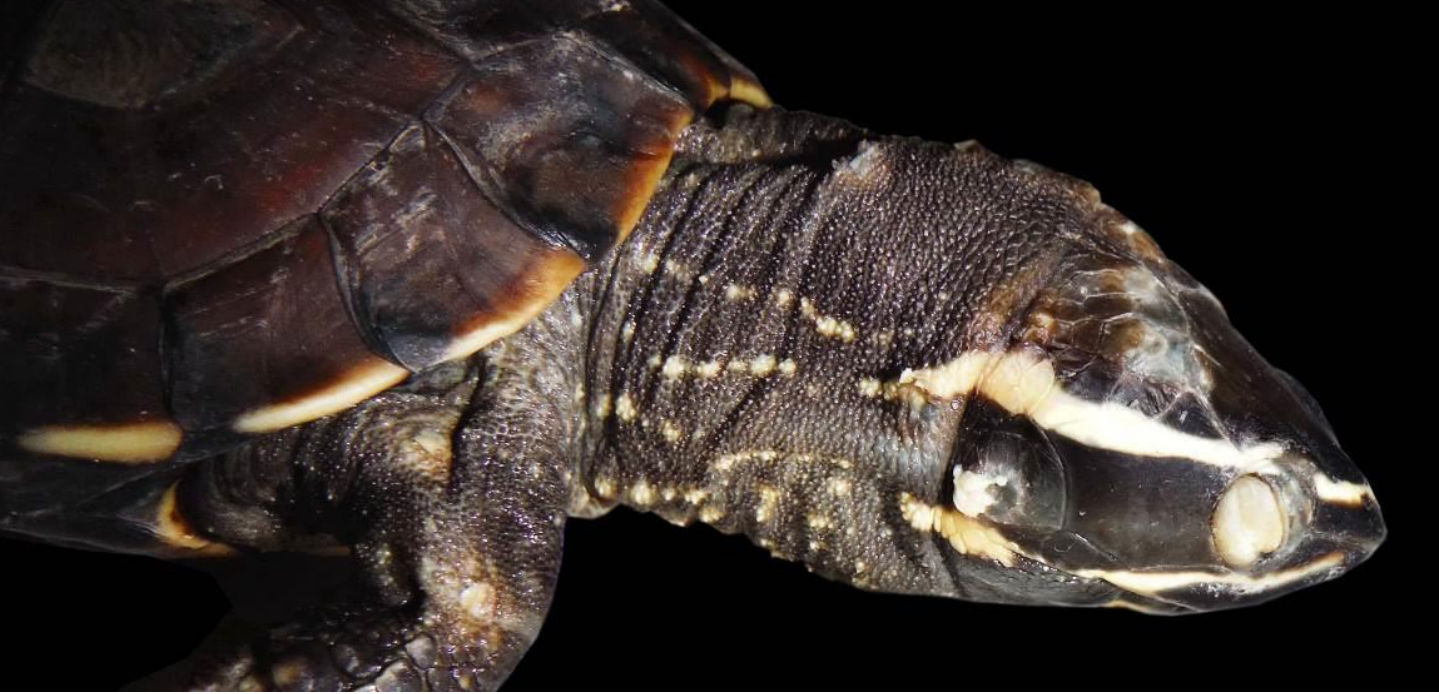

Figure 6: Lateral head views of type specimens of Malayemys isan sp. nov. (A) Paratype ZMKU Rep-000318, right side, (B) Paratype PSUZC-RT (MS 574), left side, (C) Paratype QSMI 1395, right side. 


\section{PLATE 7}
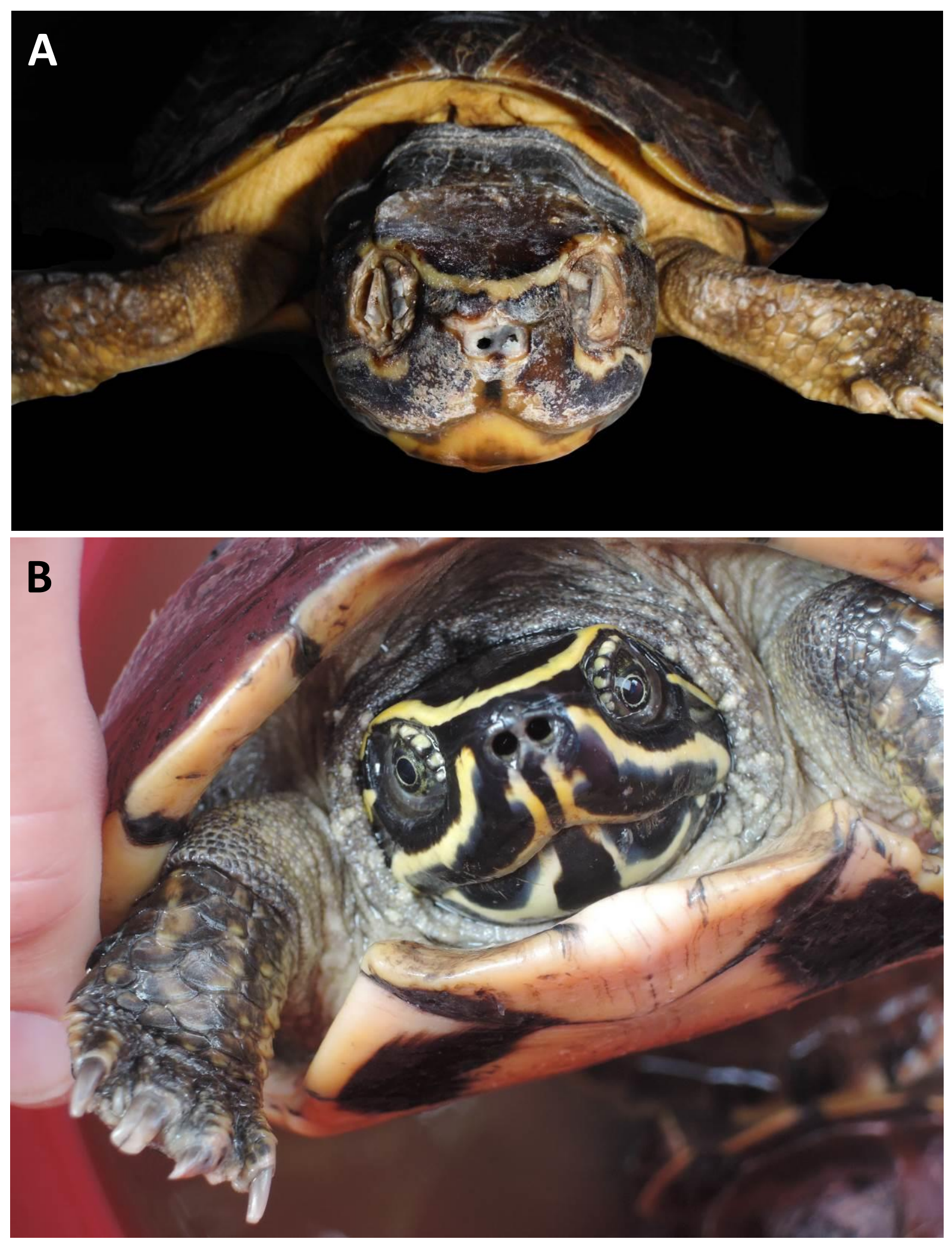

Figure 7: Front view of (A) the holotype of Malayemys isan sp. nov., showing the two nasal stripes, (B) a live adult $M$. macrocephala sold in front of a Buddhist Temple in Phetchaburi, Muang District, Phetchaburi Province to be released in the nearby Phetchaburi River. This individual features two nasal stripes and a stripe between the infra- and supraorbital stripes. 


\section{PLATE 8}

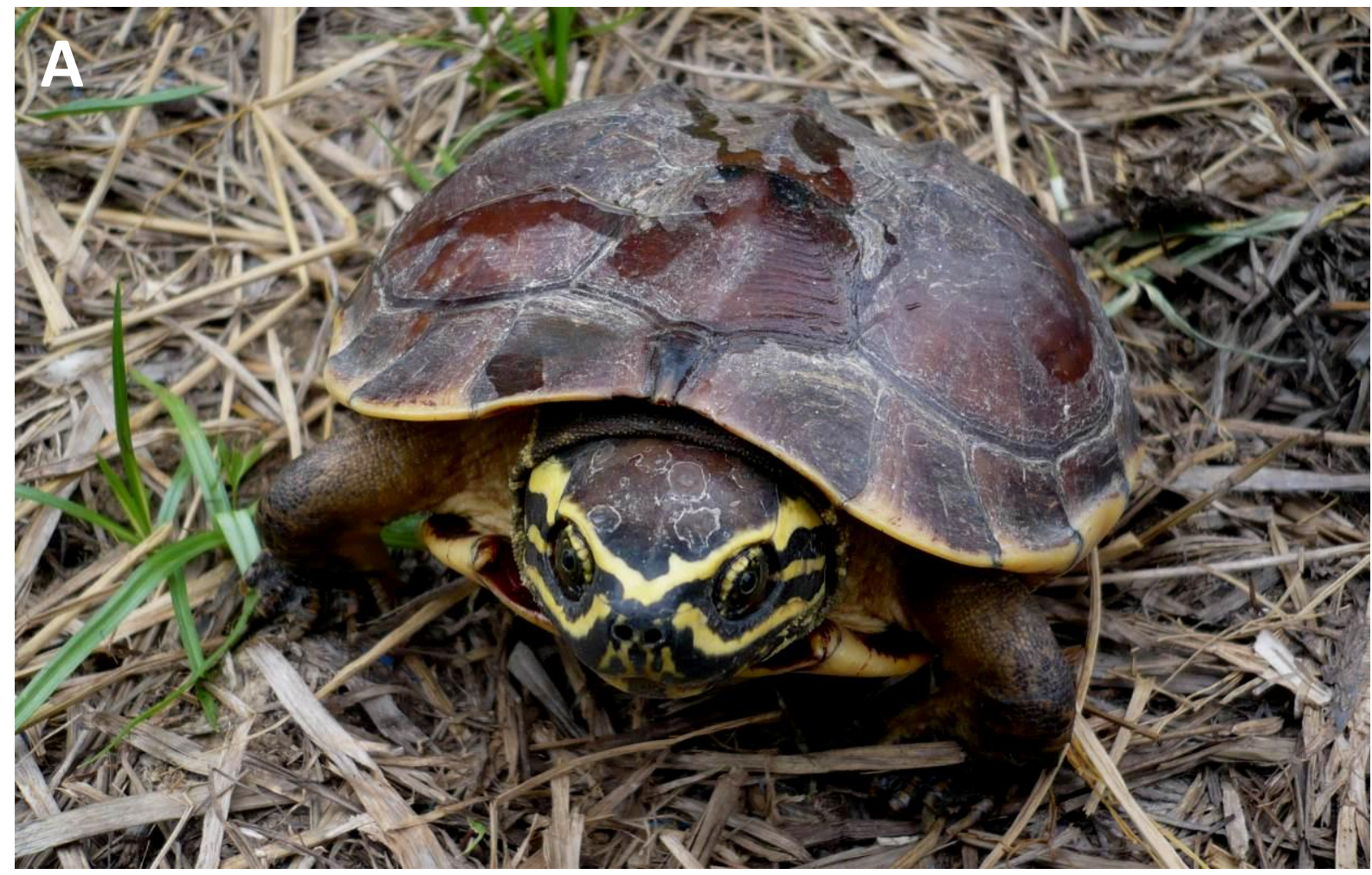

B

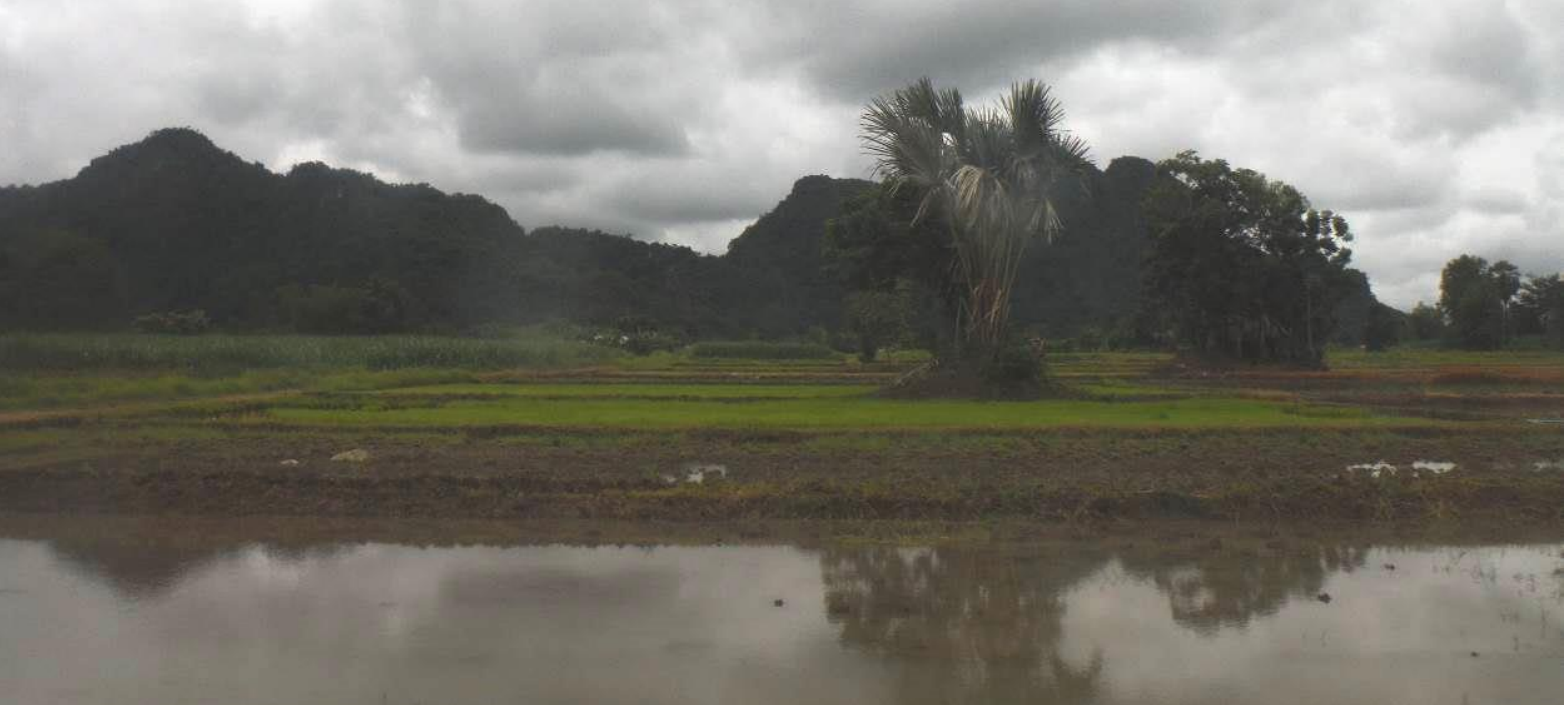

Figure 8: (A) Front view of a live adult Malayemys macrocephala caught in a rice field in Banlat, Banlat District, Phetchaburi Province. This individual features four nasal stripes and a stripe between the infra- and supraorbital stripes, (B) Macrobiotope of Malayemys isan sp. nov. in Nong Bua Lamphu, Nong Bua Lamphu Province. The turtles were found in the foreground. 


\section{PLATE 9}
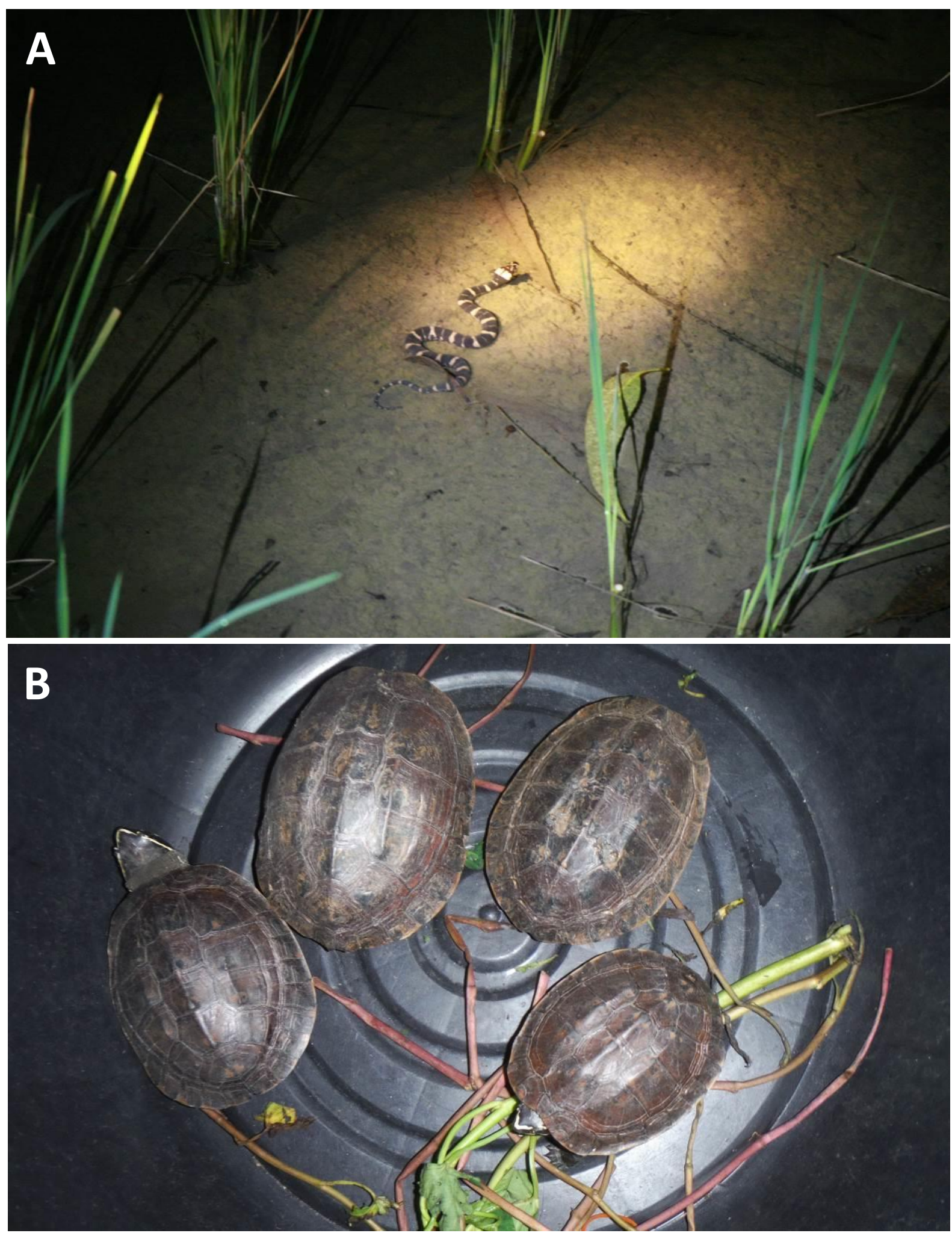

Figure 9: (A) Microbiotope of Malayemys isan sp. nov. in Nong Bua Lamphu, Nong Bua Lamphu Province, where the turtles were found by night. Note the presence of a freshwater snake Homalopsis nigroventralis (Homalopsidae) found in syntopy with the turtles, (B) Four Malayemys isan sp. nov. sold in Nong Bua Lamphu food market. All individuals were locally collected and showed the same head stripe pattern as the holotype. 


\section{PLATE 10}

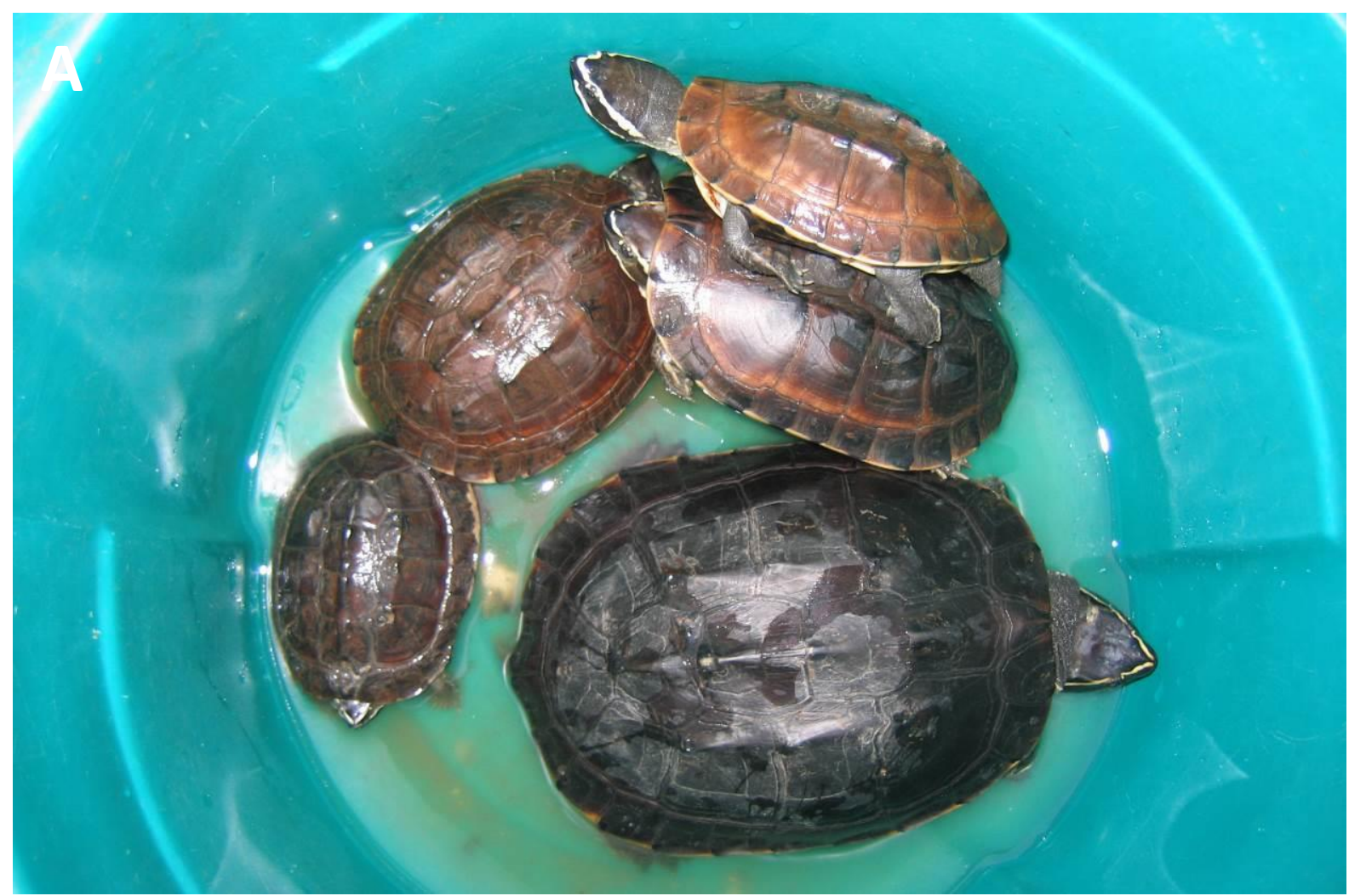

Figure 10: Five Malayemys isan sp. nov. sold in Udon Thani food market. All individuals were locally collected and showed the same head stripe pattern as the holotype. 